Revista de Ciencias Sociales - Número 67 (2015) - Páginas 127-149

La protección de bienes jurídicos como función del Derecho Penal...

\title{
LA PROTECCIÓN DE BIENES JURÍDICOS COMO FUNCIÓN DEL DERECHO PENAL. EXPANSIÓN AL ÁMBITO ECONÓMICO
}

\author{
THE PROTECTION OF JURIDICAL GOODS AS \\ FUNCTION OF THE PENAL LAW. THE EXPANSION \\ TO THE ECONOMIC ENVIRONMENT
}

\author{
MANUEL ALBERTO LEYVA ESTUPIÑÁN* \\ Universidad de Holguín (Cuba) \\ mleyva@fh.uho.edu.cu \\ LARISBEL LUGO ARTEAGA** \\ Universidad de Holguín (Cuba)
}

\section{Resumen}

La mayoría de los penalistas contemporáneos consideran que el Derecho Penal protege bienes jurídicos. Sin embargo, las diferencias teóricas aparecen cuando definimos el contenido del bien jurídico. Consideramos que estos protegen valores fundamentales y se derivan de la constitución como

* Profesor de Derecho Penal. Licenciado en Derecho por la Universidad de Camagüey, Cuba. Máster en Derecho Penal por la Universidad de Holguín, doctorando en Ciencias Jurídicas por la Facultad de Derecho de la Universidad de Oriente, Cuba. Dirección postal: Vecino de Calle 16 No 3L, Reparto Piedra Blanca, Holguín, CP 80100, Cuba. Artículo recibido el 30 de enero de 2015 y aceptado el 14 de abril de 2015.

* Profesora de Derecho Penal Especial en la Universidad de Holguín, Cuba. Licenciada en Derecho por la Universidad de Camagüey, Cuba. Se desempeñó como jueza en el Tribunal Provincial Popular de Camagüey en su Sala Quinta de lo Penal. Máster en Derecho Penal por la Universidad de Holguín.

Revista de Ciencias Sociales - Número 67 (2015) - Universidad de Valparáíso - ISSN 0716-7725-Valparáiso, Chile 
norma suprema de un país. En este panorama emerge una concepción sustentada en la sociedad del riesgo, donde la expansión del Derecho Penal se nos presenta como la garantía de la seguridad ciudadana. Dicha expansión implica la creación de nuevos bienes jurídicos de naturaleza colectiva, incluyendo propios del ámbito económico.

\title{
Palabras Clave
}

Bienes jurídicos, ius puniendi, Derecho Penal Mínimo, valores.

\begin{abstract}
Most of the specialists of the penal right at the present time consider that the penal right protects juridical goods. However, the theoretic differences appear when we defined the contents of the goods juridical. We considered that these protect fundamental values and they come from the constitution as supreme law of a country. In this scenario appear a conception based in the society of the risk where they present us the expansion of the penal right as guarantee of the citizen security. This expansion implies the creation of new juridical goods of collective nature including of the economic environment.
\end{abstract}

\section{Keywords}

Juridical goods, ius puniendi, Minimum Penal Law, values.

\section{Introducción}

La sociedad contemporánea, inmersa en encontrar el equilibrio entre inseguridad ciudadana y garantías, se replantea cuáles han de ser los bienes jurídicos tutelados por los ordenamientos penales de orden sustantivo. Lo anterior equivale a un redimensionamiento del rol del Derecho Penal ante los cada vez más complejos problemas que afectan la humanidad. Resulta difícil imaginar un escenario que apunte a la desaparición de esta forma de control social formal, tal y como proponen abolicionistas convencidos. Posterior al fatídico 11 de septiembre del 2001, el fantasma del terrorismo, la sociedad del riesgo y el Derecho Penal de Autor entre otras tendencias del punitivismo contemporáneo apuntan hacia la maximización de la norma penal.

Facultad de Derecho y Ciencias Sociales - Universidad de Valparaíso - Chile 
Los defendidos límites normativos ${ }^{1}$ del Derecho Penal sobre la base de criterios funcionalistas (correcta interpretación del ámbito de protección de la norma penal) o garantistas (adecuación correcta de los medios formales de aplicación del poder punitivo con la constitución) resultan — a mi modo de ver - inexistentes, si se parte de que el propio poder instituido sería el que limitaría su poder punitivo.

El fin del Derecho Penal no es lograr la vigencia de la norma como afirma JAKOBS, tampoco lo es de manera directa la protección de bienes jurídicos, sino que el fin del Derecho Penal desde otra óptica es el mantenimiento de un orden social determinado. Y es precisamente el conjunto de bienes a los cuales el legislador ha elevado a la categoría de bienes jurídicos fundamentales, el centro de interés de los grupos hegemónicos. Penalizando los ataques a los bienes más preciados de una sociedad se garantiza de manera indirecta el orden social deseado.

Recordemos que el derecho en sentido general constituye una de las herramientas del Estado y este, es una máquina destinada a la opresión de una clase por otra, una máquina llamada a mantener sometida a una sola clase todas las demás clases subordinadas. Lo anterior no contradice la tutela a los bienes jurídicos, pues estos encarnan de manera indirecta una protección digamos de segundo orden. El poder estatal define que se protegerá, más allá de las grandes o sutiles diferencias entre intereses, aspiraciones, valores o relaciones sociales, por solo citar algunos de los clásicos contenidos asignados al bien jurídico, estos "son producidos" por el mismo ente responsable de la punición al ataque de los mismos. Por tanto resulta incoherente afirmar que el bien jurídico constituye un límite al ius puniendi, pues quien detenta este define cuáles han de ser los bienes jurídicos a proteger. Representa una autolimitación, realizable en el plano abstracto, pero sin contenido en la realidad social.

El liberalismo limitó los excesos del poder autoritario, en favor de una clase en ascenso que reclamaba cuotas de poder político. Como

1. SCHONFELD, Leonardo Augusto "La expansión del Derecho Penal como política demagógica y sus límites”. http://www.alfonsozambrano.com/ doctrina_penal/expansion_dpenal1.pdf. Consultado el 17 de junio del 2014. SILVA SÁNCHEZ, Jesús María, La expansión del Derecho Penal; Ed. Civitas, 1999, p. 18.

Revista de Ciencias Sociales - Número 67 (2015) - Universidad de Valparaíso - ISSN 0716-7725-Valparáíso, Chile 
bien afirma SILVA SÁNCHEZ, "no fueron los modelos de Estado de hace trescientos años los que expandieron el Derecho Penal; sino que la industrialización fue el factor determinante de la aparición de aquellos riesgos que "justifican" la expansión".

El Derecho Penal expansivo es una de las manifestaciones del Estado Liberal, donde esta rama del derecho constituye una herramienta - acaso la primera - a que se echa mano cuando en campañas electorales se aborda el flagelo de la criminalidad.

SCHONFELD refiriéndose a la impronta de Feuerbach y la teoría de la coacción psicológica así como su influencia en penalistas como JACKOBS, concluye en que si el principio de legalidad estuvo en la génesis del pensamiento penal, hoy influye en su sobredimensionamiento. "a los defensores... del derecho penal moderno les corresponde el onus de responder explicativo-radicalmente por la crisis del derecho penal de nuestros tiempos. Onus de responder y explicar por la raíz iluminista, no cabiendo simplemente insistir con propuestas utopistas reincidentes en las equivocaciones fundacionales que exactamente permitieron el nacimiento de una crisis substantiva del derecho penal".

El ius puniendi como derecho a castigar según la concepción predominante, se manifiesta en el segundo momento, el de la persecución penal, que en el caso cubano equivale al monopolio estatal en el ejercicio de la acción penal. "[...] el ius puniendi ha de ejercerse en la sola medida exigida por la protección de la sociedad, es el llamado “carácter fragmentario" del Derecho penal. Significa que el Derecho penal no sanciona todas las conductas lesivas de bienes jurídicos, sino sólo las modalidades de ataque más peligrosas para ellos" ${ }^{3}$.

La configuración y delimitación de los bienes jurídicos a tutelar por las normas penales pudiera considerarse como uno de los límites internos, que nace de la propia norma. Sin embargo es el propio estado, bajo cualquiera de las interpretaciones posibles, quien fija qué bienes jurídicos o elementos de estos se protegen.

2. MARQUES DIP, Ricardo Henry; "Principio de Legalidad, Realidad y Mito". En: Prudentia Iuris, EDUCA 2002, pág. 146 nota 56.

3. MIR PUIG, Santiago, Introducción a las bases del Derecho penal, Ed. Bosch, Barcelona-España, 1976, pág. 126.

Facultad de Derecho y Ciencias Sociales - Universidad de Valparaíso - Chile 
La protección de bienes jurídicos como función del Derecho Penal...

\subsection{La protección de bienes jurídicos como función del Derecho Penal}

Las funciones del Derecho Penal se confunden en ocasiones con las funciones de la norma jurídico-penal o las funciones de la pena. Al ser la pena la consecuencia jurídica por la conducta delictiva, las funciones propias de la sanción y las funciones del Derecho Penal se interrelacionan dialécticamente. En relación a las funciones de las penas y las medidas de seguridad (contenido de esta rama del derecho que lo define con un carácter dual) han existido desde las teorías retributivas, de la prevención ${ }^{4}$ general, especial y criterios mixtos, que son los más extendidos. Las funciones de la pena estarán estrechamente relacionadas con las funciones del Derecho Penal, en el sentido de proteger un sistema social determinado. BUSTOS RAMÍRES 5 expresa que los fines de la pena están enmarcados en la imposición del capitalismo, así la pena "no podía tener sino las mismas características y constituir un medio más para realizar el objetivo capitalista”.

En la actualidad es mayoritario ${ }^{6}$ el criterio que sostiene que el Derecho Penal se encarga de la protección de bienes jurídicos. JAKOBS contrapone la vigencia de la norma como función del Derecho Penal a la concepción predominante ${ }^{7}$ enfocada en la protección de bienes

4. Las teorías de la prevención han sido criticadas por ROXIN quien argumenta dos serias razones. 1ra: Hay muchos delitos en los que no se ha podido demostrar la eficacia de la pena $2^{\text {a }}$. Fundar la ejecución de la pena en la necesidad de intimidar a la colectividad supondría utilizar al condenado como instrumento, castigarle no por lo que ha hecho, sino para que los demás no delincan.

5. BUSTOS RAMÍREZ, Juan. Bases Críticas de un Nuevo Derecho Penal. Ed. Temis, Bogotá, 1982. Págs. 115-119.

6. JAKOBS sostiene que "el derecho penal garantiza la vigencia de la norma, no la protección de bienes jurídicos”. Cfr JAKOBS, Günther, “¿Qué protege el Derecho Penal: bienes jurídicos o la vigencia de la norma”. Ediciones Jurídicas Cuyo, Argentina, año 2001, págs. 28 y 29.

7. Cfr. ROXIN, Claus; "Derecho Penal. Parte General. Tomo I. Fundamentos. La estructura de la Teoría del Delito”. Editorial Civitas 1997, pág. 52.

BACIGALUPO, Enrique; "Manual de Derecho Penal”. Tercera reimpresión. Editorial Temis. Santa Fe de Bogotá. 1996. Pág. 6. JOACHIM RUDOLPHI, Hans; "El fin del

Revista de Ciencias Sociales - Número 67 (2015) - Universidad de Valparáiso - ISSN 0716-7725-Valparáís, Chile 
jurídicos, el profesor de Bonn nos recuerda al maestro KELSEN al defender en una de sus obras cumbres "La Teoría Pura del Derecho" (1935) el concepto del derecho como entidad autónoma de concepciones ideológicas y morales.

SANCINETI ${ }^{8}$, también afirma que la idea de un derecho penal como protector de bienes jurídicos resulta expansiva del poder punitivo, pues si se pretende erigir a la amenaza de pena en un escudo protector de bienes, qué más conveniente que "incrementar el grosor de ese escudo" (incrementar las penas) para lograr una más eficaz protección. Y, adicionalmente, añade que tal protección no puede ser realizada fácticamente ${ }^{9}$.

"Si el Derecho penal realmente pudiera cumplir la misión de "proteger bienes jurídicos" en sentido físico, como si fuera un vidrio blindado que se levantase delante de los bienes, ciertamente sería correcto aumentar el grosor del vidrio tanto como fuera posible, pues cuanto más denso fuese el blindaje, mayor sería la protección. Pero esa noción es errada. La ley penal no es un "escudo protector"; ni pretende, ni puede lograr que el delito desaparezca. Ésa no es una misión que deba serle adscripta como cosa propia ni siquiera en forma ideal. No es que por el hecho de que la ley penal sea incapaz de cumplir esa misión deba desaparecer: sólo significa que no "protege", al menos no si por "protección" se entiende un "escudo real contra el agresor eventual".

Derecho penal del Estado y las formas de imputación jurídico-penal". En: "El sistema moderno del Derecho penal: Cuestiones fundamentales. Estudios en honor de CLAUS ROXIN en su 50 Aniversario. Compilado por BERND SCHÜNEMANN. Introducción, traducción y notas de JESÚS-MARÍA SILVA SÁNCHEZ. Editorial Tecnos, Madrid 1991. Pág. 82. PUIG MIR, Santiago; "Introducción a las bases del Derecho Penal". Euros Editores. Buenos Aires 2003, pág. 147. ZAFFARONI, Eugenio Rául; Tratado de Derecho Penal. Parte General. Tomo I. Ediar. Argentina 1998, pág. 24. QUIRÓS PÍREZ, Renén; "Manual de Derecho Penal. Tomo I. Editorial Félix Varela, La Habana 1999, pág. 158.

8. SAnCinetTi, Marcelo, A., Casos de Derecho penal. Parte general, Hammurabi, $3^{\text {a }}$ ed., Buenos Aires, 2006, pág. 53.

9. KIERSZENBAUM, Mariano; El bien jurídico en el Derecho Penal. Algunas nociones básicas desde la óptica de la discusión actual. Lecciones y Ensayos No $86 / 1999$.

Facultad de Derecho y Ciencias Sociales - Universidad de Valparaíso - Chile 
El Derecho Penal según ROXIN cumple una doble función: protección de bienes jurídicos y de los "fines públicos de prestación imprescindibles. Visto desde otro escenario podemos afirmar que las funciones del Derecho Penal son la protección de los bienes jurídicos y la motivación de conductas respetuosas, ajustadas al orden social y jurídico establecido por normas legales.

En el estudio del bien jurídico, habitualmente se considera que este constituye un límite al ius puniend $i^{10}$, generalmente aceptado como derecho a castigar del Estado. Más que derecho subjetivo del estado ${ }^{11} \mathrm{o}$ como potestad del Estado para castigar ${ }^{12}$ a nuestro modo de ver

10. La concepción tradicional del ius puniendi como derecho a castigar del estado resulta a nuestro modo de ver, incorrecta. Desde una concepción liberal ciertamente podría defenderse la categoría derecho, lo cual refuerza criterios como la existencia de una relación cuasi-contractual entre estado e individuo. ¿Por qué nace en el individuo que comete un delito la obligación de sufrir una pena? Desde una posición marxista, que niega llevar al plano contractual las relaciones estado- sociedad civil, más que derecho debe considerarse potestad y deber. Potestad porque solo el Estado está legitimado a través de sus órganos jurisdiccionales para dictar las leyes y perseguir los delitos. Constituye a la vez un deber que se sustenta en las funciones del Estado. El Estado tiene el deber de delimitar las conductas constitutivas de delito y la obligación —no derecho- a perseguirlas y sancionarlas. La razón de ser del Estado es precisamente garantizar la coexistencia, la estabilidad de la sociedad, tiene encomendado ese rol. Para poder cumplirlo de forma satisfactoria deberá prohibir y penal determinadas conductas, a fin de poder proteger de manera efectiva los bienes jurídicos políticamente importantes para la clase dominante. $C f r$. FONTÁN BALESTRA, Carlos. "Derecho Penal. Introducción y Parte General". ABELEDOPERROT. Buenos Aires 1998. Págs. 14 y 15. ZAFARONI, Eugenio Raúl. Tratado de Derecho Penal. Parte General. Tomo I. EDIAR. Buenos Aires, Argentina 1998. Págs. 33 y ss.

11. SOLER, Sebastián; Derecho Penal Argentino. Tipográfica Editora Argentina. Buenos Aires.1992. Pág 13. MIR PUIG, Santiago. Ob. Cit. Pág. 98, MEDINA CUENCA, Arnel; Los principios limitativos del ius puniendi. Su incidencia en la determinación de la pena y su consagración en las constituciones nacionales y en los instrumentos jurídicos adoptados por la comunidad internacional. Trabajo de investigación defendido en opción del título de Máster en Derecho público, en el Departamento de Derecho Penal de la Facultad de Derecho de la Universidad de Valencia, España, mayo del año 2001.

12. NÚÑEZ, Ricardo C.; Manual del Derecho Penal Parte General. Cuarta Edición Actualizada por Roberto E. Spinka y Félix González. Editorial Córdoba. Argentina 1999, pág. 15. QUINTERO OLIVARES, G. habla de "potestad punitiva” en Represión penal y Estado de Derecho, Barcelona,1976, pág. 37.

Revista de Ciencias Sociales - Número 67 (2015) - Universidad de Valparáíso - ISSN 0716-7725-Valparaíso, Chile 
constituye un límite en sí mismo, límite formal, pues estaríamos hablando del estado auto limitándose en sus funciones. En nuestro criterio el ius puniendi constituye un deber ${ }^{13}$, una obligación (Obligatio ad faciendum) generada por las propias funciones del Estado.

Las discutidas relaciones entre Derecho-Ideología, DerechoMoral, Derecho-Política en alguna medida pierden su razón de ser cuando se advierte que todo derecho, y fundamentalmente el que encuentra asidero en normas positivas, es un reflejo de las aspiraciones de la clase dominante, que por intermedio del Derecho, como herramienta valiosísima, conculca en los ciudadanos su sistema de valores. Como afirma el profesor sevillano MUNOZ CONDE ${ }^{14}$ los "bienes jurídicos son producidos".

Si en el pasado se podía construir la ideología imperante a partir del dominio político de determinada clase social, hoy resulta difícil, delimitar qué intereses se tutelan, no puede hablarse de un grupo homogéneo ideológicamente hablando. Detrás del estado contemporáneo no son los partidos o movimientos políticos o sociales los que determinan las pautas, sino los grandes intereses económicos, mayormente trasnacionales. El Derecho Penal al definir que protege de manera efectiva, que conductas sanciona, lo hace - y es lamentable que así suceda - para satisfacer al gran capital, no a las mayorías.

La discusión cae entonces en que es lo que debe ser considerado como bien jurídico. La mayoría de los autores ${ }^{15}$ difieren en la concepción sobre el bien jurídico.

13. Autores como CARBONELL MATEU plantean que "ha de considerarse indiscutible que no se trata del ejercicio de ningún derecho subjetivo, sino de las funciones que corresponden al Estado en virtud del pacto social traducido en la Constitución. El poder de crear normas penales no tiene diferentes características que el de legislar en materia de cultura, obras públicas o educación, si bien, a diferencia de esas materias, y como ya sabemos, el Derecho penal supone recortes a la libertad general con el fin de tutelar las libertades de los ciudadanos". Cfr. CARBONELL MATEU, Juan Carlos. Derecho Penal: concepto y principios constitucionales. $2^{\text {a }}$ ed., adaptada al Código Penal de 1995. Tirant lo blanch. 1996, pág. 102.

14. HASSEMER y MUNOZZ, Conde "Introducción a la Criminología y al Derecho Penal”. España, Ed. Tirant lo Blanch, 1989, pág. 111.

15. JUARES E.X., Tavarez; Bien jurídico y función en el Derecho penal, colección Claves del Derecho Penal, n³, ed. Hammurabi, pág. 67. FERRAJOLLI, Luigi;

Derecho Penal Mínimo y Bienes Jurídicos fundamentales". Revista Ciencias Penales.

Facultad de Derecho y Ciencias Sociales - Universidad de Valparaíso - Chile 
Desde el punto de vista histórico se ha asociado a los derechos subjetivos, ya criticados en su momento por MEZGER cuando exponía ejemplos de delitos donde no se atacaban bienes jurídicos. También ha sido considerado como interés, lo cual reduce el significado del término, pudiendo existir bienes jurídicos que no generen un interés propiamente dicho en su titular. COBO DEL ROSAL y VIVES ANTÓN ${ }^{16}$ traen a manera de ejemplo la vida como bien jurídico y varias situaciones donde la misma no constituya un interés, para su titular.

El concepto ${ }^{17}$ del derecho subjetivo (como derecho natural del hombre) se fundó entonces en la afirmación del poder del individuo para reclamar el respeto absoluto de los derechos inherentes a su persona y bienes. Los derechos subjetivos del individuo constituían derechos naturales del hombre, no derivados de norma jurídica alguna.

Inicialmente el Derecho se encargó de la tutela de bienes jurídicos individuales que coincidían con los llamados derechos constitucionales de primera generación como son la vida, la integridad corporal, el honor etc. Según El-khoury Jacob, no se debe perder de vista que el concepto

Asociación de Ciencias Penales de Costa Rica. Disponible http://www.cienciaspenales. org/ferraj05.html [Consultado el 17 de junio del 2014] CHIRINOS SÁNCHEZ, Alfredo y HENRY ISSA, El —KHOURY JACOB; Bien jurídico y derecho de castigar del Estado. Comentarios sugeridos por una sentencia de la Sala Constitucional. Revista de la Sociedad de Ciencias Penales de Costa Rica. ROXIN, Claus, Derecho Penal Parte General Tomo I. Fundamentos. La estructura de la teoría del delito. Traducción de la 2da Edición alemana. Editorial Civitas SA. Madrid. España 1997. Pág. 55. BIMBAUM, Über das Erfordernis einer Rechtsverletzung Zum Begrif des Verbrechens en Archiv des Criminalrechts, Neue Folge 1834. BIMBAUM, JOHANNN MICHAEL FRANZ, Sobre la necesidad de una lesión de derechos para el concepto de delito, colección Maestros del Derecho Penal, ed. BdF, n 32, 2010. DE LA CUESTA AGUADO, Paz M. Norma primaria y bien jurídico: su incidencia en la configuración del injusto (VII). SUÁREZ LÓPEZ, Beatriz Eugenia; “¿Existe el bien jurídico-penal en el siglo XXI? Premio Francisco Tomás y Valiente de la Universidad de Barcelona. 2009. BUSTOS RAMÍREZ, Juan J. y HORMAZÁBAL MALARÉE, Hernán; Lecciones de Derecho Penal. Volumen I. Editorial Trotta. Madrid 1997, pág. 58.

16. COBO Del ROSAL, M., VIVES ANTÓn, T. M., Derecho Penal: Parte General; 3ra. Edición corregida y actualizada, Tirant lo Blanch, pág. 249.

17. QUIRÓS PÍREZ, Op. Cit. Pág. 151.

Revista de Ciencias Sociales - Número 67 (2015) - Universidad de Valparaíso - ISSN 0716-7725-Valparáiso, Chile 
de bien jurídico, de acuerdo con HASSEMER “es obra del pensamiento de la ilustración”. Lo fundamentó y formuló PAUL JOHANN ANSELM FEUERBACH como arma contra una concepción moralizante del Derecho Penal. Para ROXIN el concepto se debe a BIMBAUM ${ }^{18}$ quien desarrolla este concepto en el año 1834. Con este autor aparece un nuevo punto de partida en la idea de un concepto de bien jurídico, no netamente subjetivo, porque parte de la premisa que detrás de ese derecho hay algo más que se quiere proteger, un interés que es su razón de ser y que surge a partir de un concepto natural y positivo del derecho. BIMBAUM le da un vuelco a estas consideraciones al sostener que debían de ser bienes tutelados por el Estado.

FERRAJOLI parte de un análisis sobre lo que merece tutela penal, en sus distintas etapas partiendo de los iluministas (FEUERBACH y HUMBOLDT, de BENTHAM y CONDORCET, a FILANGIERI, ROMAGNOSI, PAGANO y CARMIGNANI) para quienes debía ser necesariamente un derecho subjetivo natural de la persona.

Los idealistas objetivos con su máxima figura, GUILLERMO FEDERICO HEGEL quien abstrayéndose de "lo que es justo en su existencia" al "derecho en sî", de la parte lesionada "al universal lesionado" caminan por senderos idealistas que no representan la verdadera magnitud del concepto de bien jurídico. Resulta entendible si partimos de que el derecho es una parte más de la superestructura social, asentada sobre determinada base económica.

IHERING y BINDING lo analizan sobre la base de lo que "pueda servir al interés del estado" o lo que "tiene valor a los ojos del legislador". El bien jurídico, desde una función utilitarista, se identifica con la validez de la norma. Desde esa perspectiva el bien jurídico entendido como un valor de la persona humana de carácter universal, material o ideal, pero real, y que se lo describe como "la relación de disponibilidad de un sujeto para con un objeto".

Para Jescheck el bien jurídico ha de entenderse como valor ideal del orden social jurídicamente protegido, en cuyo mantenimiento tiene interés la comunidad y que puede atribuirse, como su titular, tanto al

18. Para el profesor QUIRÓS PÍREZ la construcción del bien jurídico es anterior a BIMBAUM. Vid Manual de Derecho Penal. Tomo I. Editorial Félix Varela, La Habana 2005, pág. 182.

Facultad de Derecho y Ciencias Sociales - Universidad de Valparaíso - Chile 
particular como a la colectividad. En cuanto categoría puramente formal el bien jurídico es además el género de todo los objetos individuales que incluye el fin de protección de la norma”" ${ }^{19}$.

Como afirma FERRAJOLI, el problema del bien jurídico no es otra cosa más que el problema de los fines del Derecho Penal. Para el eminente penalista italiano un programa de Derecho Penal mínimo debe entonces apuntar hacia una masiva deflación de los bienes penales actualmente tutelados por la ley, por lo tanto a una drástica reducción de las prohibiciones legales, como condición de su legitimidad política y jurídica ${ }^{20}$. A partir de lo que hoy conocemos como principio de lesividad u ofensividad no tiene razón de existir un Derecho Penal que no lesione o al menos ponga en peligro bienes jurídicos. “(...) el bien jurídico es el criterio central para determinar el merecimiento de pena que, para salvaguardar, de algún modo los derechos de las distintas partes intervinientes en un conflicto penal" ${ }^{\text {. }}$.

El profesor ROXIN considera que el bien jurídico, por tanto, es el bien ideal que se incorpora en el concreto objeto de ataque; y es lesionable sólo dañando los respectivos objetos individuales de la acción ${ }^{22}$. El penalista alemán lo considera como circunstancias dadas o finalidades que son útiles para el individuo y su libre desarrollo en el marco de un sistema social global estructurado sobre la base de esa concepción de los fines o para el funcionamiento del propio sistema ${ }^{23}$. Para declarar una conducta como delito no debería bastar que suponga una infracción de una norma ética o divina, es necesario ante todo la prueba de que lesiona intereses

19. ESTRADA VÉLEZ, Federico; Derecho Penal Parte General. Editorial Hammurabi S.R.L., 2ª Edición. Año 1998, pág. 181.

20. FERRAJOLI, Op. Cit., pág. 7.

21. CASELl LÓPEZ, Magaly, "La Política Criminal” Colectivo de autores. Ed. Félix Varela. La Habana, Cuba 2004 citando Hans Jescheck Heinrich "Nueva Dogmática y Política Criminal en Perspectiva comparada". Anuario de Derecho Penal y Ciencias Penales, Tomo 39, Fascículo I, 1986.

22. Ídem, pág. 63.

23. Ídem, pág. 56.

Revista de Ciencias Sociales - Número 67 (2015) - Universidad de Valparáíso - ISSN 0716-7725-Valparaíso, Chile 
materiales de otras personas, es decir, de que lesiona bienes jurídicos"24. ZAFFARONI lo define así: “...bien jurídico penalmente tutelado es la relación de disponibilidad de un individuo con un objeto, protegida por el Estado, que revela su interés mediante la tipificación penal de conductas que le afectan"25.

Por bienes jurídicos entiende CALLIESS no "substanciales" (Substanzialen) ni "valores o bienes", sino "particípales" \{Partizipalien). Protección de bienes jurídicos significa "protección de las posibilidades de participación en la sociedad”. La estructura que protege el derecho penal garantiza la seguridad de comportamiento y de expectativas para el sujeto activo y el sujeto pasivo: se sabe cómo hay que comportarse y cabe esperar que el otro se comportará en consecuencia ${ }^{26}$.

COBO DEL ROSAL y VIVES ANTÓN consideran de manera sintética que constituye todo valor de la vida humana protegido por el Derecho $^{27}$.

MUNOZZ CONDE ${ }^{28}$ plantea que son los presupuestos que la persona necesita para la autorrealización en la vida social.

Desde otro punto de vista puede valorarse de la siguiente manera:

1. En el sentido político criminal: (de lege ferenda) Aquello que merece ser protegido por el Derecho Penal.

2. En el sentido dogmático: (de lege data) De objeto efectivamente protegido por la norma penal vulnerada de que se trate.

24. HASSEMER, Winfried, Fundamentos del Derecho Penal, Barcelona, España, Editorial BOSCH, 1984, pág. 37.

25. ZAFFARONI, Eugenio Rául; Manual de Derecho Penal, Buenos Aires, EDIAR, 1989, pág. 289.

26. MIR PUIG, Santiago. "Introducción a las bases del Derecho Penal". 2da. Edición. Euros Editores S.R.L. Buenos Aires, Argentina 2003, pág. 72.

27. COBO DEL ROSAL, M., VIVES ANTÓN, T. M., op. cit.; pág. 249.

28. MUÑOZ CONDE, Francisco. Introducción al Derecho Penal. Editorial Bosch, Barcelona, 1975, pág. 91.

Facultad de Derecho y Ciencias Sociales - Universidad de Valparaíso - Chile 


\subsection{El bien jurídico como valor}

En la doctrina cubana contemporánea QUIRÓS PÍREZ al igual que el español BUSTOS RAMÍREZ se afilia a la teoría de la relación social como sustento del bien jurídico, Magister dixit al referirse al concepto como "las relaciones sociales o elementos de las relaciones sociales que, por su particular interés social, son protegidas por medio del Derecho Penal, de los ataques y amenazas materializados por comportamientos considerados socialmente peligrosos" 29 . Resulta por tanto atinado ubicar la estrecha relación entre bien jurídico y antijuricidad. Las relaciones sociales más importantes para la sociedad no adquieren la condición de bien jurídico per se, sino que necesitan estar tuteladas por una norma penal.

En la actual sociedad del riesgo algunos autore ${ }^{30}$ valorando las $^{2}$ críticas $^{31}$ que se formulan a la teoría del bien jurídico, algunas de ellas desde una multiplicidad de definiciones, centran el debate en torno al surgimiento del bien jurídico. La primera de las posiciones parte de su consideración como objeto de protección del Derecho Penal (siendo la protección de bienes jurídicos y la motivación las principales funciones que se le reconocen al mismo), debe la existencia a partir del reconocimiento por el derecho positivo. Considero que los bienes jurídicos constituyen el conjunto de valores de los individuos y la sociedad políticamente organizada. Lo anterior legitima la despenalización de aquellas conductas que no representan un riesgo real y grave $e^{32}$ a la humanidad.

\footnotetext{
29. QUIRÓS. Op. Cit. Pág. 118.

30. Ídem, pág. 2.

31. KAKOBS afirma que la verdadera función del Derecho Penal no es la protección de bienes jurídicos, sino la protección de la vigencia de la norma.

32. Esta idea concreta la concepción del Derecho Penal, como un derecho de última ratio. También explica una de las funciones del bien jurídico; la interpretación. Por tanto el Derecho Penal como última de las opciones protege subsidiariamente los bienes jurídicos defendidos también por otras ramas.
}

Revista de Ciencias Sociales - Número 67 (2015) - Universidad de Valparáíso - ISSN 0716-7725-Valparáiso, Chile 
Los estudiosos ${ }^{33}$ que siguen las premisas de VON LISZT consideran al bien jurídico como un interés vital preexistente al ordenamiento jurídico, vital para el desarrollo de los individuos de una sociedad determinada, que adquiere reconocimiento jurídico.

Como hemos reiterado nuestra visión del bien jurídico parte de considerarlo como valores, que no existen independientes de la realidad, sino que son condicionados por ella. Los valores no existen fuera de las relaciones sociales, fuera de la sociedad y el hombre, y poseen un carácter histórico concreto, ya que lo que tiene significación positiva en un momento, la pierde en otro y viceversa ${ }^{34}$.

Los teóricos del marxismo han insistido en el contenido sociohistórico de los valores y la jerarquía de valores dentro de un sistema. En materia penal son esos valores fundamentales los que son tutelados.

No puede concebirse el derecho como un ente abstracto. La norma, por encima de cualquier otra consideración, lleva en sí los valores y aspiraciones del grupo políticamente dominante en la sociedad. Hablar de bien equivale necesariamente a hablar de valor, pero no todo valor relevante al derecho constituye bien jurídico penal.

Desde una función sistemática el bien jurídico permite valorar la lesión o el peligro a que ha sido sometido, lo que lleva a que asuma un rol dentro del ilícito penal, no ya como elemento en la estructura del tipo penal o permita la configuración de familias delictivas, sino como requisito sine qua non. Sin ataque al bien jurídico no existe delito. Lo anterior atribuye al bien jurídico una función de garantía; existirá la pena allí donde hay un bien jurídico lesionado, y no cualquiera, sino los más importantes para la sociedad.

El autor coincide con lo expresado por el profesor de Múnich ${ }^{35}$ en relación a la derivación de los bienes jurídicos de la Constitución, en

33. KIERSZENBAUN, Mariano. "El bien jurídico en el Derecho Penal. Algunas nociones básicas desde la óptica de la discusión actual". Lecciones y ensayos. No 86, 2009. P. 1 y 2. En: http://www.derecho.uba.ar/publicaciones/lye/revistas/86/ 07-ensayo-kierszenbaum.pdf [Consultado el 8 de septiembre del 2014].

34. FABELO, José Ramón. Práctica, conocimiento y valoración. La Habana. Editorial de Ciencias Sociales, La Habana, 1989, págs. 31-37.

35. ROXIN, Claus. "Derecho Penal. Parte General. Fundamentos. La estructura de la teoría del delito. Tomo I". Traducción de la Segunda Edición alemana. Editorial CIVITAS S.A. Madrid, España, 1997, pág. 55.

Facultad de Derecho y Ciencias Sociales - Universidad de Valparaíso - Chile 
tanto ésta plasma los límites al poder punitivo del Estado. Valorar la derivación constitucional de los bienes jurídicos tutelados por normas penales, implica asumir que los movimientos constituyentes reflejan conquistas sociales llevadas al plano jurídico con una fuerte carga axiológica, pero también intereses económicos, políticos e ideológicos. La existencia de cláusulas pétreas en las constituciones o el posterior inmovilismo a la hora de dictar las normas complementarias a la Carta Magna, reflejan donde está el poder real, y es este poder el que decide qué y cómo castigar.

Los principios de última ratio y lesividad, limitadores al ius puniendi del estado condicionan determinados requisitos para que un valor o interés sea tutelado por el Derecho Penal. Ese valor debe representar una derivación de los valores superiores recogidos en la Constitución, no sólo norma jurídica suprema, sino también proyecto político aspirado. Así como esta categoría ha de desprenderse de los valores defendidos en la constitución, es menester aclarar que dichos valores, así como los bienes finalmente tutelados podrán ser siempre objeto de discusiones, tanto por ausencias como por excesos. Discusiones estas que olvidan el carácter clasista del Estado y el Derecho, al responder a una ideología determinada, el legislador no hace sino proteger aquellos intereses del grupo dominante. Cierto es que pueden ocurrir desfases temporales con los valores defendidos por la propia ideología, pero finalmente las modificaciones en la norma positiva suplen estas carencias. Termina así el Estado, siendo también objeto de tutela del Derecho Penal ${ }^{36}$.

Nuestra visión del bien jurídico parte de considerarlo como aspiraciones, valores, ideales, que no existen independientes de la realidad, sino que son condicionados por ella, manifestándose en las fundamentales relaciones sociales que se producen. No puede concebirse el derecho como un ente abstracto.

Desde un enfoque indirecto, al protegerse bienes jurídicos de naturaleza penal se está garantizando la estabilidad política y social del

36. Los delitos contra la Seguridad del Estado, contra la economía nacional, contra la administración y jurisdicción, por solo citar algunos ejemplos, manifiestan bien de manera directa o bien de manera accesoria, la condición del Estado como objeto de tutela del Derecho Penal.

Revista de Ciencias Sociales - Número 67 (2015) - Universidad de Valparáíso - ISSN 0716-7725-Valparaíso, Chile 
sistema, se está otorgando a esas aspiraciones clase una significación positiva, constituyendo diferente de mantener dicha estabilidad, no ya por medio de la coercitividad propia de las normas jurídicas, sino mediante formas de dominación y consenso construidas desde la contradicción entre el ser y el deber ser, entre lo justo y lo injusto. Habrá que entender a estos valores como "la significación socialmente positiva que adquieren los objetos y fenómenos de la realidad al ser incluidos en el proceso de actividad práctica humana" ${ }^{\text {37 }}$. Es a través de los valores aspirados, llevados a la condición de bien jurídico que se logra la función motivacional del Derecho Penal. Existe por tanto una relación dialéctica entre que se protege y lo que se desea lograr. Protegiendo valores se conculcan los valores deseados.

En materia de negociación de contratos la trascendencia penal generalmente se configura a partir de la afectación a bienes jurídicos de naturaleza colectiva como el buen funcionamiento de la administración o la economía nacional entre los más recurrentes. En este caso debe estar plenamente justificada la aplicación en el campo penal del ilícito cometido, no ya como una afectación en la esfera de lo privado sino en el ámbito de lo público. Además de la delimitación entre dolo civil y dolo penal, en el campo civil el daño ocasionado debe ser susceptible de apreciación, mientras que en lo penal debe verificarse la lesión o puesta en peligro de un bien jurídico penal tutelado.

\subsection{La expansión del Derecho Penal en el ámbito económico: ¿Creación de nuevos bienes jurídicos?}

La expansión de las normas penales potenciada por la globalización económica y que encuentra asidero en una sociedad enfrentada a nuevos y viejos riesgos latentes conduce inexorablemente al redimensionamiento del alcance, pero también eficacia del Derecho Penal contemporáneo. Cuando los autores modernos ${ }^{38}$ analizan el

37. FABELO, Op.Cit. Pág. 43.

38. SCHONFEL, Leonardo. La expansión del Derecho Penal como política demagógica y sus límites. Cfr. www.carlosparma.com.ar Consultado el 13 de agosto del 2014. ESCOBAR BELTRÁN, Samuel Augusto. La expansión del Derecho Penal.

Facultad de Derecho y Ciencias Sociales - Universidad de Valparaíso - Chile 
fenómeno de la expansión generalmente se aborda el fenómeno desde una expansión — que en nuestro criterio catalogamos_ hacia adelante. Aumentan los tipos penales, aparecen nuevas figuras agravadas, se incrementan los delitos de peligro, se protegen bienes jurídicos colectivos etc.

El tránsito de un Derecho Penal protector de bienes jurídicos individuales, clásicos, hacia nuevos objetos de tutela penal puede ser asumido como una manifestación del proceso de expansión que se ha producido en las últimas décadas. El Medio Ambiente, la seguridad colectiva, la economía nacional o el buen funcionamiento de la administración y jurisdicción no aparecían en los primeros códigos de derecho canónico del medioevo. El nuevo escenario en materia económica hacia donde confluyen las normas penales está presente en momentos donde la globalización convierte al planeta en la aldea global.

Los cambios que se han producido en el entorno económico mundial a partir de la globalización económica y el propio desarrollo de la sociedad imponen transformaciones al sistema de relaciones sociales y jurídicas existentes. Se justifican las normas penales que crean nuevos delitos cuando estos surgen al adaptarse la sociedad a estos nuevos escenarios. Es entendible entonces que aparezcan nuevos delitos, pero también que desaparezcan otros.

Hay un grupo de causas objetivas que han incidido en esta expansión. Ya mencionábamos la globalización económica, y la permanente sensación de peligro de la sociedad moderna, en buena

Análisis de las capacidades auto restrictivas de los sistemas modernos del delito a partir de la libertad de expresión. MENDOZA BREMAUNTZ, Enma. Globalización, internacionalización del delito y seguridad. SILVA SÁNCHEZ, Jesús María. La expansión del Derecho Penal. Aspectos de la política criminal en las sociedades postindustriales. Cuadernos Civitas. Disponible en http://bibliotecajuridicaargentina.blogspot.com SERRANO TÁRRAGA, María Dolores, La expansión del Derecho Penal en el ámbito de la delincuencia económica. La tutela penal de los mercados financieros. Revista de Derecho de Valdivia, Vol. XVIII N ${ }^{\circ}$ 1, julio 2005, pp. 213-237. Disponible en http:// mingaonline.uach.cl/scielo.php? pid $=$ S0718-09502005000100009\&script $=$ sci_arttext Consultado el 14 de junio del 2014. MORILLAS CUEVAS, Lorenzo, El Derecho Penal mínimo o la expansión del Derecho Penal. Escuela de verano de la Habana sobre temas penales contemporáneos. La Habana 2005.

Revista de Ciencias Sociales - Número 67 (2015) - Universidad de Valparáíso - ISSN 0716-7725-Valparaíso, Chile 
medida formada por los medios hegemónicos de comunicación. Como diría SILVA SÁNCHEZ citando a GARAPÓN ${ }^{39}$ :

"los medios, que son el instrumento de la indignación y de la cólera públicas, pueden acelerar la invasión de la democracia por la emoción, propagar una sensación de miedo y de victimización e introducir de nuevo en el corazón del individualismo moderno el mecanismo del chivo expiatorio que se creía reservado para tiempos revueltos (...) Los asesinatos de niños se convierten en acontecimientos nacionales para una opinión pública fascinada por la muerte y la transgresión. Su exasperación por los medios acabará por hacer creer al ciudadano no avisado que este tipo de crímenes es frecuente, lo que no es el caso".

Otro de los elementos apunta al desarrollo tecnológico y su utilización por la delincuencia inter y trasnacional, que ha llevado a los estados a la búsqueda y aplicación de nuevas formas y maneras de lucha contra el delito, que en algunos casos y de manera lamentable, afectan garantías y principios básicos de la dignidad humana.

El intercambio económico mundial genera mayores volúmenes de comercio. Ante un mayor número de operaciones aduaneras, financieras y contables mayores posibilidades de ilícitos se manifiestan. Como afirmara hace ya algunas décadas Manuel López Rey y Arrojo ${ }^{40}$ (...) el delito ya no es la entidad científica elaborada por destacados criminólogos sino un fenómeno sociopolítico en proceso de rápida expansión, estrechamente relacionado con la estructura global de la sociedad, que no puede identificarse con la imagen de un establishment determinado, sea capitalista o socialista.

Desde otra perspectiva se hace uso del Derecho Penal — a nuestro modo de ver - como herramienta eficaz en la detección y combate rápido y eficiente pues logra un efecto determinado sobre las formas de actuar fraudulentas y extremadamente lesivas a la economía de un país. Lo que no queda del todo asegurado es la eficacia de esas mismas normas penales, los fines a los que se aspira.

39. GARAPÓN, Juez y democracia, Barcelona, 1997, págs. 94 y ss.

40. LÓPEZ REY Y ARROJO, Manuel. La criminalidad. Un estudio analítico. Ed. Tecnos. Madrid 1976, pág. 352.

Facultad de Derecho y Ciencias Sociales - Universidad de Valparaíso - Chile 
La expansión es metafóricamente hablando un avance veloz del Derecho Penal por las autopistas de la economía, no ya tras el delincuente tradicional mal vestido, mal educado y producto de barrios marginales, sino una marcha a toda velocidad, en ocasiones sin clara noción del final del viaje, ante la marcha rezagada de un Derecho Administrativo extenso, enrevesado y vulnerable que no es capaz de prevenir y sancionar eficazmente a un corporativo elegante y extremadamente capacitado. En vez de cuchillos y armas de fuego hablamos de contratos, negociaciones, operaciones millonarias, rostros felices ante cámaras de televisión que auguran un desarrollo económico impetuoso. Al cabo de los meses o años es que aparecen las defraudaciones, el daño al país y a su gente. Casi siempre el corporativo elegante disfruta en su país de los millones robados, mientras se procesa penalmente a funcionarios de mediano rango que tuvieron la desdicha de aportar sus rostros como acusados.

Dentro de este auge, ha venido surgiendo una criminalidad económica, cuyos perfiles delictivos son cada vez más sofisticados y complejos, asunto que admite necesariamente incluir métodos efectivos de enfrentamiento, investigación, persecución y sanción a la delincuencia económica, coherente y racionalmente en atención a la agresividad, nocividad y afectaciones que se producen por la ocurrencia de estas conductas transgresoras de la ley penal.

La función de garantía del bien jurídico puede constituir la primera barrera en el sentido de descongestionar las leyes penales y dotarlas del necesario carácter subsidiario del Derecho Penal. La llamada función reductora del Derecho Penal implicaría que éste es tremendamente ineficaz cuando se le tiene por la herramienta principal para el desarrollo económico de un país. Los mecanismos económicos para la solución de conflictos, tanto los tradicionales como los alternativos siempre serán menos onerosos que la solución penal.

En los procesos asociados a formas de contratación económica se manifiestan delitos que destacan por el carácter pluriofensivo de los mismos. Varios son los bienes jurídicos afectados por las conductas de los agentes económicos comisores de delitos. En los procesos contractuales, aun en su etapa de negociación, ciertamente pueden vulnerarse bienes jurídicos tutelados por las normas penales. El problema no radica

Revista de Ciencias Sociales - Número 67 (2015) - Universidad de Valparáíso - ISSN 0716-7725-Valparaíso, Chile 
en penar todas estas conductas. La génesis radica en el análisis exegético que se realice de lo tutelado por los tipos penales. Y — en primerísimo lugar-delimitar conscientemente qué conductas han de sancionarse.

En los delitos económicos donde existe un sujeto definitivamente diferente al delincuente tradicional, podrían realizarse las mismas preguntas que ZAFFARONI formula en su ponencia sobre la lógica del carnicero y el Derecho Penal. ¿Qué fines se logran, además de la represión del delito, cuando se envía a prisión por largos años a un individuo que en la negociación de un contrato ha afectado los intereses económicos del país o el buen funcionamiento de la administración?

¿Se protegen realmente bienes jurídicos al configurar tipos penales que sancionan las conductas impropias de los funcionarios en los procesos de negociación de contratos? ¿Estas normas realmente motivan al resto de los individuos al respeto de la Ley? En pocas ocasiones se logra la recuperación de los activos defraudados. Consideramos que el fin preventivo pocas veces se logra, este tipo de delincuencia crece y se expande ante la ineficiencia del Derecho administrativo. No es el temor a la sanción penal lo que evita la comisión de estos delitos, sino la existencia real y eficiente de mecanismos de control en las propias entidades.

Que el Derecho Penal no logre sus fines (efectiva protección de bienes jurídicos y motivación de los ciudadanos hacia el respeto al orden social y jurídico) resulta preocupante, pero más peligroso aun consiste en una expansión desenfrenada hacia más Derecho Penal.

Más allá de la cuestión relativa a la capacidad de una puesta en peligro abstracto de bienes jurídicos supraindividuales para constituir un injusto que fundamente culpabilidad, en derecho penal económico se presenta un problema de culpabilidad más específico aún. Pues el reproche ético-jurídico de la pena no sólo tiene por objeto el fracaso del autor en un rol social específico, sino que lo afecta en todos los espacios de ejercicio de sus roles y, con ello, en todos sus roles. De esta forma, la pena apunta al ser humano como persona, es decir, como aquel sujeto que es libre y responsable en la vida social.

Dentro de este panorama de necesidad de prevención masiva y prevención de riesgos, se desarrolla el derecho penal económico. Probablemente, de ahí proviene la penuria de crear tipos penales como

Facultad de Derecho y Ciencias Sociales - Universidad de Valparaíso - Chile 
los de peligro, estudiados hasta el momento. Estos delitos de peligro abstracto, que a diferencia de los tipos penales de lesión, en los primeros no hay daño a un objeto concreto, solo hay un peligro en la producción de la lesión, son un claro ejemplo de lo que sucede en la materia.

Esta necesidad de prevenir riesgos futuros, acaece en el derecho penal moderno, olvidando las funciones que tenían las garantías y principios en el derecho penal clásico. Y aunque la doctrina lo advierta, el legislador es poco renuente a aceptar una reducción del derecho penal, posiblemente por las presiones sociales y de prensa a las que son sometidos los legisladores.

\section{Conclusiones}

Es a partir de la Ilustración y el desarrollo del Derecho Natural donde se empiezan a formular con mayor claridad los necesarios límites al poder absoluto de los monarcas. Como periodo histórico representa el auge de la concepción según la cual el Derecho Penal protegía los derechos subjetivos de los ciudadanos. Este periodo representa una etapa de ruptura con el pasado inquisitivo y a la vez de construcción de una nueva teoría garantista.

Salvo contados autores, la mayoría de los penalistas contemporáneos consideran que la protección de bienes jurídicos constituye una de las funciones del Derecho Penal. A la hora de definir qué entendemos por bien jurídico las respuestas varían según la escuela o tendencia a la cual se acogen los autores del pasado y el presente. Entre las diversas concepciones pueden mencionarse los que consideran que se trata de un interés vital, de una relación social, de valores, etc.

En nuestro modesto criterio, y considerando el derecho penal como rama dentro de un ordenamiento jurídico complejo y dinámico, que responde a distintas variables de funcionamiento, los bienes jurídicos pueden ser identificados con los valores fundamentales reconocidos y derivados de la constitución como norma suprema. Los bienes jurídicos son producidos, creados según intereses económicos, políticos y sociales.

En la actual sociedad de riesgo está teniendo lugar un proceso de expansión del Derecho Penal, que implica la creación de bienes 
jurídicos colectivos, creación de tipos penales de peligro abstracto y formas de anticipación de la tutela penal, por solo citar algunas de sus manifestaciones. Esta expansión en la esfera de lo económico, socaba las bases de un Derecho Penal mínimo y su necesario carácter subsidiario. Encontrar formas distintas a la penal para la solución de los graves problemas económicos que aquejan a la humanidad representará menores costos para la justicia y formas más expeditas de resolver los conflictos sociales.

\section{BIBLIOGRAFÍA}

ASÚA BATARRITA, Adela. "Reivindicación o superación del programa Beccaria”. En: Asúa Batarrita, Adela, ed., El pensamiento penal de Beccaria: su actualidad, Bilbao, Ed. Universidad de Deusto, 1990.

Birnbaum, Über das Erfordernis einer Rechtsverletzung Zum Begrif des Verbrechens en Archiv des Criminalrechts, Neue Folge, 1834.

BUSTOS RAMÍREZ, Juan. Bases Críticas de un Nuevo Derecho Penal. Ed. Temis, Bogotá, 1982.

CASELL LÓPEZ, Magaly. "La Política Criminal” Colectivo de autores. Ed. Félix Varela. La Habana, Cuba 2004 citando Hans Jescheck

Heinrich "Nueva Dogmática y Política Criminal en Perspectiva comparada". Anuario de Derecho Penal y Ciencias Penales, Tomo 39, Fascículo I, 1986.

ESTRADA VÉLEZ, Federico. Derecho Penal Parte General. Editorial Hammurabi S.R.L., 2 ${ }^{\text {a }}$ Edición, 1998.

FERRAJOLI, Luigi. Derecho y Razón. Teoría del garantismo Penal. Editorial Trotta, 1995.

__ Derecho Penal Mínimo y Bienes Jurídicos fundamentales. Revista Ciencias Penales. Asociación de Ciencias Penales de Costa Rica. Disponible http://www.cienciaspenales.org/ferraj05.html Consultado el 17 de junio del 2014.

GARCÍA PABLOS, Antonio. "Tendencias del Actual Derecho Penal”. Modernas Tendencias en la ciencia del Derecho Penal y en la Criminología. Universidad Nacional de Educación a Distancia. Congreso Internacional, Actas y Congresos. Madrid. España, 2000.

Facultad de Derecho y Ciencias Sociales - Universidad de Valparaíso - Chile 
La protección de bienes jurídicos como función del Derecho Penal...

HASSEMER y MUÑOS CONDE. "Introducción a la Criminología y al Derecho Penal” . España, Ed. Tirant lo Blanc, 1989.

HASSEMER Winfried, Fundamentos del Derecho Penal, Barcelona, España, Editorial BOSCH, 1984.

_ Fundamentos del Derecho Penal, Barcelona, España, Editorial BOSCH, 1984.

JAKOBS, Günther, “¿Qué protege el Derecho Penal: bienes jurídicos o la vigencia de la norma”. Ediciones Jurídicas Cuyo, Argentina, año 2001.

JUARES E.X. Tavarez; Bien jurídico y función en el Derecho penal, colección Claves del Derecho Penal, n³, ed. Hammurabi, pág. 67.

KIERSZENBAUN, Mariano. "El bien jurídico en el Derecho Penal. Algunas nociones básicas desde la óptica de la discusión actual". Lecciones y ensayos. $\mathrm{N}^{\circ}$ 86, 2009. pp.1 y 2. En http://www.derecho. uba.ar/publicaciones/lye/revistas/86/07-ensayo-kierszenbaum.pdf Consultado el 8 de septiembre del 2014.

LÓPEZ REYY ARROJO, Manuel. La criminalidad. Un estudio analítico. Ed. Tecnos. Madrid, 1976.

MIR PUIG, Santiago. "Introducción a las bases del Derecho Penal". 2 da. Edición. Euros Editores S.R.L. Buenos Aires, Argentina, 2003.

NÚÑEZ, Ricardo C.; Manual del Derecho Penal Parte General. Cuarta Edición Actualizada por Roberto E. Spinka y Félix González. Editorial Córdoba. Argentina 1999.

QUIRÓS PÍREZ, Renén, "Manual de Derecho Penal. Parte General". Tomo I. Editorial Félix Varela, La Habana, 1999.

SÁNCHEZ, Alfredo y HENRY ISSA El -KHOURY JACOB; Bien jurídicoy derecho de castigar del Estado. Comentarios sugeridos por una sentencia de la Sala Constitucional. Revista de la Sociedad de Ciencias Penales de Costa Rica.

SILVA SÁNCHEZ, Jesús María, La expansión del Derecho Penal; Ed. Civitas, 1999.

SOLER, Sebastián; Derecho Penal Argentino. Tipográfica Editora Argentina. Buenos Aires, 1992.

ROXIN, Claus, Derecho Penal Parte General Tomo I. Fundamentos. La estructura de la teoría del delito. Traducción de la 2da. Edición alemana. Editorial Civitas SA. Madrid. España, 1997.

ZAFFARONI, Eugenio Raúl, Manual de Derecho Penal, Buenos Aires, EDIAR, 1989.

Revista de Ciencias Sociales - Número 67 (2015) - Universidad de Valparáíso - ISSN 0716-7725-Valparaíso, Chile 